\title{
Uniões homossexuais masculinas legais
}

\section{Ana Maria Marques \\ Professora do Departamento de História E Programa de pós-graduação em História da UFMT}

Lopes, Moisés. Homens como outros quaisquer: subjetividade e homoconjugalidade no Brasil e na Argentina. Jundiaí: Paco Editorial, 2012.

Homens como outros quaisquer: subjetividade e homoconjugalidade no Brasil e na Argentina é o título do livro de Moisés Lopes, publicado pela Paco Editorial (Jundiaí/SP), em 2012. A publicação é resultado de tese de doutorado em Antropologia defendida pelo autor em 2010, na Universidade de Brasília, sob orientação da Prof ${ }^{a}$ Lia Zanotta. $O$ enunciado remete à questão da norma: o que faz do homem um qualquer? Os traços da masculinidade: macho, másculo, viril. Características que não se constituem, necessariamente, em oposição à feminilidade. Ou seja, o macho não precisa da fêmea para se afirmar como tal, ao contrário do que denunciava Simone de Beauvoir quando escreveu, em 1949, O segundo sexo. Para Beauvoir (1970), a mulher se constitui como o Outro do Homem - sujeito universal. Quaisquer porque, mesmo relacionando-se sexualmente com homens, em nada se diferenciam de outros machos, cujo estereótipo condiz com um 
padrão de apresentação de cabelos, roupa, postura e forma corporal, e também impostação de voz.

A pesquisa antropológica de Moisés Lopes acompanhou o momento importante dos debates sobre a legalização das uniões homoconjugais estáveis e, posteriormente, do casamento entre pessoas do mesmo sexo, em especial na última década. O tema esteve na pauta das reivindicações sobretudo do movimento LGBT (Lésbicas, Gays, Bissexuais, Travestis, Transexuais, Transgênero), antes mesmo que a sigla e suas várias denominações fossem essas. Em 14 de maio de 2013, o Brasil deu um passo decisivo para a equiparação do casamento civil, independentemente se entre pessoas do mesmo sexo ou do sexo oposto, com a aprovação pelo Supremo Tribunal Federal da resolução que obriga os cartórios de todo o país a celebrar o casamento civil igualitário.

Moisés acompanhou o debate acerca da legalização do casamento igualitário desde o seu mestrado, iniciado em 2002 na Universidade Estadual de Londrina, quando investigou a Parceria Civil Registrada de homossexuais". Depois, em 2004, uma pesquisa sobre conjugalidade homossexual masculina levou-o a Cuiabá. O doutorado, iniciado em 2006, permitiu-lhe ir a Buenos Aires para pesquisar a homoconjugalidade masculina e, assim, traçar um comparativo entre Brasil e Argentina, tendo as duas capitais federais como campo de pesquisa. Diga-se de passagem, a Argentina foi o primeiro país da América Latina a criar lei de matrimônio para casais do mesmo sexo, assinada pela Presidenta Cristina Kirchner em 2010.

A metodologia utilizada para a pesquisa antropológica apresenta-se também como uma proposta inovadora, considerando a recorrente imagem do antropólogo como aquele que vai até o grupo pesquisado, vive um tempo lá, para depois escrever sobre os nativos. O nativo para Moisés Lopes não é o "natural de uma terra", na definição do dicionário Aurélio (1985). É um grupo de pessoas com quem ele tem contatos pessoais, sim: entrevista, frequenta lugares comuns de sociabilidade, mas não são necessariamente pessoas do lugar. Alguns se remetem ao seu histórico de migração ou de seus familiares. Em comum, os nativos têm a opção conjugal - o laço estável que une dois homens por anos a fio. Os casais foram garimpados em persistente jogo de "sedução" através de dois sítios eletrônicos de relacionamento na internet e, também, entre amigos de amigos. O passo a passo é contado com detalhe no livro e envolve o leitor na trama que provocou pessoas a se voluntariarem à pesquisa - e que exerceu fascínio no próprio pesquisador.

Os treze casais que se dispuseram a conceder entrevistas e generosamente expor suas relações íntimas têm um perfil comum, salvo uma ou outra exceção: são homens majoritariamente brancos, de classe média e de pouca diferença etária. Mesmo considerando esse recorte, que permitiria

Uso o termo "homossexual" ou "homossexuais", em vez de "homoafetivos" ou "homoeróticos", concordando com a escolha do autor, que aciona o argumento de Michel Foucault quando atenta sobre a importância que a sexualidade assume na modernidade para a compreensão das identidades. 
vislumbrar uma perspectiva étnica, racial, etária, de classe e de gênero, vê-se um campo de subjetividades. Tanto em Brasília (cinco casais) como em Buenos Aires (oito casais), os nativos apresentam modos de pensar e agir que se diferem na maneira como encaram a relação quanto a: oficialização pelas vias legais da união estável, fidelidade e assumir a homossexualidade conjugal. Sobre cada um desses três pontos vale refletir em separado.

Para alguns, a união estável não precisa chegar ao casamento civil, pois eles asseguram a propriedade comum, no caso de um dos dois faltar, através de contrato e de colocar os bens em nome dos dois. Todavia, todos defendem o casamento como um direito que garante o reconhecimento da igualdade entre casais sem diferenciar o sexo, mesmo que para um ou outro isso pouca ou nenhuma diferença faça. Vale salientar que alguns casais, dentre o universo pesquisado, são parcialmente oriundos de casamentos heterossexuais, cujas relações resultaram em filhos, inclusive. Ou seja, a vida em casal, de opção homo, não é um fim, nem um começo de vida conjugal, para estes.

Para os entrevistados por Lopes, a fidelidade, em geral, não é pensada de maneira clássica como compromisso sexual restrito ao casal. A fidelidade é subjetivada, colocando a traição no campo abstrato dos sentimentos. Logo, a traição, inimiga da fidelidade, seria aos sentimentos. Trair a si, aos sentimentos partilhados pelo casal, isto sim seria ser infiel. Então, a palavra que traduz melhor o compromisso dos casais é a lealdade. “(...) a fidelidade, para todos os interlocutores, está ligada a um sentimento, está vinculada ao amor e não ao sexo" (p. 134). Vale ressaltar que muitos casais entendem a fidelidade de maneira estereotipada vivida pelos casais heterossexuais, como se para os héteros a relação conjugal não pudesse considerar as "fugidas" e aventuras sexuais como parte aceitável ou tolerável na relação dos casais, desde que não envolvam sentimentos.

O terceiro ponto: sobre assumir a relação publicamente. Todos os pesquisados são unânimes e concordam que tornar público o compromisso do casal é também encarar o peso da definição da opção fora da norma: a homossexualidade. Todos, com exceção de um (que se diz bissexual) se definem como homossexuais, mesmo que alguns tenham tido anteriormente relações sexuais com mulheres (p. 91). A definição em si parece ser demarcadora de identidade, característica que torna irrevogável o desejo pelo outro desvinculado do corpo masculino. Ou seja, para eles, o desejo liga-se ao corpo e não ao sentimento independente do corpo (macho ou fêmea). Apesar de todos relatarem ser bem aceitos pela família, pelos colegas de trabalho e círculos de convivência, alguns preferem não declarar a homoconjugalidade para evitar possíveis conflitos.

Assumir a homossexualidade é posto, a partir da fala dos nativos, como um evento irrevogável (p. 148). Mais complicado ainda torna-se expor uma relação conjugal com compromisso de constituir bens e, quiçá, família. A segunda parte das implicações desse assumir é ainda deveras desafiadora aos padrões de uma moralidade que se pauta em tradições religiosas, sobretudo 
cristãs, e científicas. Foucault, na História da sexualidade, vol. 2 (2001), nos ajuda a entender quanto os saberes médicos, científicos e jurídicos da modernidade fundaram uma heteronormatividade reguladora das relações sexuais. No imaginário regulador dos entrevistados, a religião aparece como pano de fundo. Mesmo não sendo praticantes assíduos desta ou daquela confissão religiosa, o pecado e o erro, não raro, rondam as consciências e interferem na decisão sobre "sair do armário".

Entretanto, assumir a sexualidade fora da norma, considerando que existe uma heterossexualidade compulsiva, é sempre conflitivo - não só para homossexuais, haja vista a recorrente negativa ou invisibilidade destinada às mulheres. Mulheres que demonstram ser desejosas por sexo, seja com homens ou mulheres, são frequentemente interpretadas como putas, fáceis, de vida vadia e outros adjetivos mais. Enquanto homens "pegadores" são bem vistos como excelentes exemplares de masculinidade. A prática sexual, quanto mais frequente, para o homem é afirmação de masculinidade, enquanto a mulher deve pautar sua conduta feminina no recato e na expiação.

No próprio universo homossexual pesquisado por Lopes, existe o reforço ao estereótipo do macho como naturalmente feito para a atividade sexual. A exemplo, cito os nomes, mesmo que fictícios, para diferenciar personagens: "creo que el varon está hecho para tener sexo todo el tempo" (Juan, p.73), "creo que hay uma parte animal com um deseo así de tener sexo y no sexo siempre com la pareja” (Esteban, p. 125). Os brasileiros têm falas semelhantes, concordando que homens sempre buscam sexo nas relações de casais. Alguma fala recorre, inclusive, ao estereótipo do casal heterossexual, no qual a presença da mulher diminui a intensidade da necessidade de sexo: "no mundo hétero você vê muito a questão do sentimento primeiro e depois o sexo. Já no mundo homo isso se inverte, é muito sexo e pouco relacionamento" (Saul, p. 125).

Ainda na definição da expressão da sexualidade, os casais em geral não se colocam como ativos ou passivos, e sim versáteis - o que remete a uma correspondência no comportamento cotidiano das tarefas domésticas. $\mathrm{Ou}$ seja, não existe a figura de quem manda, provê e domina - tudo é partilhado e negociado, também nos afazeres da casa: compras, refeições, limpeza. Novamente, lembro que a referência à família patriarcal, signo da subserviência que determinou à mulher o papel de submissa, constitui-se em teoria bastante criticada por feministas, especialmente pós-estruturalistas (Scott, 1990).

Moisés Lopes não escreveu um livro para provar, com a experiência amostral, um essencialismo, embora de maneira recorrente os entrevistados o façam em falas do tipo: sempre senti atração por homens e a opção é irreversível. $\mathrm{O}$ autor reconhece o campo de subjetividades, mesmo onde as estruturas parecem rígidas e fixas. Ele não concorda nem defende a existência de uma natureza de destino. O trabalho de Moisés nos faz refletir com a profundidade de um referencial teórico que utiliza Foucault e Butler, e 
também mergulha na produção intelectual sobre o tema da conjugalidade, sobretudo de outros/as antropólogos/as, como as brasileiras Maria Lucia Heiborn e Lia Zanotta, o português Miguel Vale de Almeida e o francês Michel Bozon. Além de sociólogos/as e historiadoras que o auxiliam. O tema da homoconjugalidade tem sido explorado na pesquisa antropológica, resultando em dissertações e teses defendidas, além de artigos publicados. $\mathrm{Na}$ forma de livro, no entanto, Moisés Lopes toma a dianteira nessa corrida acadêmica, desbravando um campo ainda muito envolto por estigmas e carente de visibilidade.

Nos dias atuais, quando presenciamos uma onda retrógrada de conservadorismo e defesas eloquentes da "família tradicional", sobretudo através de mídias televisivas e redes sociais que esbravejam discursos fundamentalistas cristãos/evangélicos e também de alas conservadoras do catolicismo, ler sobre diferentes formas de conjugalidade possíveis é, minimamente, alentador. Trata-se de obra sensível e recomendada a quem se preocupa com as discussões de gênero e não se acomoda sobre as incertezas da sexualidade.

\section{Referências Bibliográficas}

BEAUVOIR, Simone de. (1949). O segundo sexo. Parte I - Fatos e mitos. Tradução Sérgio Milliet. 4. ed. São Paulo: Difusão Europeia do Livro, 1970. FERREIRA, Aurélio Buarque de Holanda. Minidicionário Aurélio da Língua Portuguesa. Rio de Janeiro: Nova Fronteira, 1985.

FOUCAULT, Michel. História da sexualidade. V. 2. O uso dos prazeres. 9. ed. Rio de Janeiro: Graal, 2001.

SCOTT, Joan W. Gênero: uma categoria útil de análise histórica. Revista Educação e Realidade, Porto Alegre, v. 16, n. 2, p. 5-22, jul./dez. 1990. 